\title{
Synthesis and Physicochemical Characterization of Biodegradable Star-Shaped Poly Lactide-Co-Glycolide- $\beta$-Cyclodextrin Copolymer Nanoparticles Containing Albumin
}

\author{
Soodabeh Davaran ${ }^{1 *}$, Akbar Rezaei ${ }^{2}$, Somayeh Alimohammadi ${ }^{1}$, Amir Ahmad Khandaghi ${ }^{3}$, \\ Kazem Nejati-Koshki ${ }^{1}$, Hamid Tayefi Nasrabadi ${ }^{1}$, Abolfazl Akbarzadeh ${ }^{{ }^{*}}$ \\ ${ }^{1}$ Department of Medical Nanotechnology, Faculty of Advanced Medical Science, Tabriz University of Medical Sciences, \\ Tabriz, Iran \\ ${ }^{2}$ Department of Science, Ahar Branch, Islamic Azad University, Ahar, Iran \\ ${ }^{3}$ Department of Medicine, Tabriz University of Medical Sciences, Tabriz, Iran \\ Email: “davaran@tbzmed.ac.ir, akbar.rezaei@gmail.com, somayeh.alimohamadi@yahoo.com, Amirahmadkh@gmail.com, \\ Najati.k@gmail.com, Tayefih@yahoo.com, ${ }^{*}$ akbarzadehab@tbzmed.ac.ir
}

Received November 25, 2013; revised December 29, 2013; accepted January 18, 2014

Copyright (C) 2014 Soodabeh Davaran et al. This is an open access article distributed under the Creative Commons Attribution License, which permits unrestricted use, distribution, and reproduction in any medium, provided the original work is properly cited. In accordance of the Creative Commons Attribution License all Copyrights @ 2014 are reserved for SCIRP and the owner of the intellectual property Soodabeh Davaran et al. All Copyright (C) 2014 are guarded by law and by SCIRP as a guardian.

\begin{abstract}
The purposes of this research were to synthesize and characterize star-shaped poly lactide-co-glycolide- $\beta$-cyclodextrin (PLGA- $\beta$-CD) copolymer by reacting L-lactide, glycolide and $\beta$-cyclodextrin in the presence of stannous octoate as a catalyst. The structure of PLGA- $\beta$-CD copolymer was confirmed with 1H-NMR, 13C-NMR and FT-IR spectra. Albumin as a model peptide drug was encapsulated within nanoparticles made of PLGA- $\beta$-CD with a modified double emulsion method. Transmission electron microscopy (TEM) and scanning electron microscopy (SEM) photomicrographs showed that the nanoparticles have the mean diameter within the range of 80 - $210 \mathrm{~nm}$. Also they were almost spherical in shape. Effects of the experimental parameters, such as copolymer composition, copolymer concentration, and reaction temperature, on particular size and encapsulation efficiency were investigated.
\end{abstract}

\section{KEYWORDS}

\section{Albumin; Star-Shaped Poly Lactide-Co-Glycolide; $\beta$-Cyclodextrin; Nanoparticles}

\section{Introduction}

Therapeutic proteins have been recognized as a novel generation of drugs, mainly due to their highly specific activity [1,2]. Biodegradable nanoparticles as drug delivery systems for proteins or peptides have become an extremely hot topic for decades; these nanoparticles are suitable alternatives for conventional dosage forms [3,4]. As to the use of different biodegradable polymers, PLGA has been extensively used for preparation of nanoparticles due to its safety and physicochemical properties, as it is nontoxic, biodegradable and biocompatible $[5,6]$.

${ }^{*}$ Corresponding author.
The sequential resistances of this hydrophobic polymeric system are the low entrapment efficiency, the instability of entrapped hydrophilic protein, the burst release and its imperfect release thereafter $[7,8]$. To overcome demerits of PLGA, nanoparticles described above constructed novel composite nanoparticles, which were composed of biodegradable polymers [9]. Alginate and chitosan were used to form double-walled nanocapsules [10,11]. This kind of nanocapsules not only gives protein a suitable nanoenvironment by dual hydrophilic protection but also makes the initial release retarded [12]. In addition, the dual-walled nanocapsules can be more incorporated in PLGA by W/O emulsification, and the release profiles 
including the burst release and sustained release can be accommodated with the parameters of alginate, chitosan, and ratios of poly(lactic acid) (PLA) to poly(glycolic acid) (PGA) $[13,14]$. In addition, the encapsulation efficiency of the composite nanospheres is elevated evidently. Also cyclodextrins (CD) are a group of cyclic oligosaccharides obtained from the enzymatic degradation of starch [15]. They have torus form with hydrophilic outer surface and a lipophilic central hollow space [16]. These properties cause CDs to form inclusion complexes with lipophilic molecules $[17,18]$. The three most important CDs, $\alpha, \beta$ and $\gamma$, are composed of six, seven or eight $\mathrm{D}-(+)$ glucopyranose units, respectively. The aqueous solubility of a protein and drug-CD complex in particular, can be dramatically different from that of the free form. This complexation will affect many of the physicochemical properties of drug without alteration of the essential pharmacokinetic $[19,20]$. In general, they are used to enhance solubility, bioavailability and stability. Also, they protect drugs against physicochemical and enzymatic degradation [21,22]. No covalent bonds can be between the $\mathrm{CD}$ and its guest, so complexation can be considered as a dynamic procedure. Therefore, a drug including within the cyclodextrin hollow may be dissociated upon dilution, displaced by a more appropriate guest or transferred to a matrix for which it has a higher affinity, such as an organic membrane [23]. CDs have been successfully used to modify the release features of polymeric systems mainly due to their facility of forming inclusion complexes with drugs that affect drug solubility and/or diffusivity [24]. Serum albumins are the most abundant proteins in blood plasma. They aid in the transport, supply and metabolism of several endogenous and exogenous ligands [25]. So serum albumin is in use as a model for studying drug-protein interaction in vitro. Many drugs and other bioactive small molecules bind reversibly to albumin and other serum components then utility as carriers [26].

The aim of present work was to assess the merits of PLGA- $\beta$-CD nanoparticles as an albumin carrier. For this purpose, the copolymers of PLGA- $\beta$-CD were synthesized and characterized. Polymeric nanoparticles were prepared by using a precipitation-solvent evaporation technique. To study the effect of experimental parameters on the properties of these nanoparticls, different formulations of monomers were obtained and fully characterized for morphology, size and encapsulation efficiency.

\section{Materials and Methods}

\subsection{Materials}

DL-Lactide (LA), glycolide (GA), $\beta$-cyclodextrin ( $\beta$ $\mathrm{CD}$ ), and stannous octoate were obtained from Sigma
Chemical Co. (St. Louis, MO). Dichloromethane (DCM), Polyvinyl alcohol (PVA, Mw 10,000) and solvents were purchased from Merk company. The structure of copolymers was characterized by FT-IR (Shimadzu 8400, Kyoto, Japan), ${ }^{13}$ CNMR and ${ }^{1} \mathrm{H}-\mathrm{NMR}$ ((Bruker spectra spin $400 \mathrm{MHz}$, Leipzig, Germany, and their molecular weight and molecular weight distribution (polydispersity index, $\mathrm{Mw} / \mathrm{Mn}$ ) was determined by gel permeation chromatography (GPC, Waters model 515 HPLC pump, Milford, USA). Differential scanning calorimetry (DSC) was conducted in nitrogen atmosphere using a (DSC7 Perkin Elmer, Waltham, USA) calorimeter. Samples were sealed in aluminum pans and heated twice in a nitrogen atmosphere. Drug-loaded polymeric particles were lyophilized by a Christ Alpha 1 - 4 freeze dryer.

\subsection{Synthesis of $\beta$-CD-PLGA Copolymer}

$\beta$-CD-PLGA Copolymer nanoparticles of five different ratio (according to Table 1) were synthesized Bulk polymerization. LA, GA, and $\beta$-CD were heated while stirring to $40^{\circ} \mathrm{C}$, in a nitrogen atmosphere followed by the addition of $0.05 \%$ of stannous octoate. The temperature was raised to $150^{\circ} \mathrm{C}$. After 15 min the viscous mixture reacted further at $150^{\circ} \mathrm{C}$ for $10 \mathrm{~h}$. The mixture was dissolved in dichloromethane (DCM) as much as possible by boiling and the solvent was separated. The solution was treated with aqueous $\mathrm{HCl}$ solution to remove the catalyst. The solution was washed with water and diluted with DMC and added drop wise within half an hour to methanol at $-30^{\circ} \mathrm{C}$. At this temperature the mixture was stirred and the product was filtered off and lyophilized. The copolymers are referred to in the text as PLGA- $\beta$ $\mathrm{CDx}$, where $\mathrm{x}$ designates the mole $\%$ of $\beta$-CD in the copolymer.

\subsection{Preparation of Albumin-Loaded Nanoparticles}

Drug-loaded nanoparticles PLGA- $\beta$-CD nanoparticles were prepared by using a double emulsion methodevaporation $(\mathrm{W} / \mathrm{O} / \mathrm{W})$. The albumin was dissolved in $\mathrm{HCl}(0.1 \mathrm{~N})$ and added to polymer solution (with 10 wt\%) in Dichloromethane followed by homogenization in a 20,000 rpm and 60 second primary emulsion W/O was established. These emulsions added to aqueous solution of polyvinyl alcohol (PVA) and for a second time were under Homogenizer. During homogenization the temperature was fixed below $10^{\circ} \mathrm{C}$. After the formation of the emulsion $\mathrm{W} / \mathrm{O} / \mathrm{W}$ solvent was evaporated under vacuum. Nanoparticles obtained by centrifugation at $12,000 \mathrm{rpm}$ for $20 \mathrm{~min}$ and were isolated. Nanoparticles supernatants were removed and stored for subsequent experiments. 
Table1. Physical properties of star-shaped PLGA-b-CD copolymers.

\begin{tabular}{|c|c|c|c|c|c|c|c|}
\hline sample & mole ratio GA:LA & mole ratio CAT:CD:GA:LA & molecular weight & polydispersity & $\operatorname{Tg}\left({ }^{\circ} \mathrm{C}\right)$ & $\operatorname{Tm}\left({ }^{\circ} \mathrm{C}\right)$ & Yield (\%) \\
\hline PLGA- $\beta$-CD (I) & 0.1:0.3 & 0.05:0.1:0.25:0.75 & 12,770 & 3.3 & 85 & 182 & 65 \\
\hline PLGA- $\beta$-CD (II) & $0.1: 0.2$ & 0.05:0.1:0.35:0.65 & 10,580 & 3.2 & 72 & 155 & 60 \\
\hline PLGA- $\beta$-CD(III) & 0.1:0.1 & 0.05:0.1:0.50:0.50 & 10,058 & 5.4 & 48 & 145 & 52 \\
\hline PLGA- $\beta$-CD(IV) & $0.2: 0.1$ & 0.05:0.1:0.65:0.35 & 8695 & 7.2 & - & 120 & 40 \\
\hline PLGA- $\beta$-CD (V) & 0.3:0.1 & 0.05:0.1:0.75:0.25 & 7225 & 8.4 & - & 110 & 28 \\
\hline
\end{tabular}

\subsection{Characterization of $\beta$-CD-PLGA Copolymer}

\subsubsection{Fourier Transforms Infrared Spectroscopy}

FT-IR spectra obtained by FT-IR spectrophotometer (Shimadzu 8400, Kyoto Japan) for blank and drug loaded nanoparticles using $\mathrm{KBr}$ discs.

13CNMR and 1H-NMR spectroscopy

The chemical structures of the copolymers were determined by 13 CNMR 1H-NMR (Bruker spectra spin $400 \mathrm{MHz}$, Leipzig, Germany).

\subsubsection{Study of Thermal Properties}

Glass transition temperature (Tg) was determined using differential scanning calorimetric measurements (DSC7 Perkin Elemer, Waltham, USA). All measurements were conducted in crimped nonhermetioc aluminium pans by heating the samples at a rate of $10^{\circ} \mathrm{C} / \mathrm{min}$ from 20 to $200^{\circ} \mathrm{C}$, with an empty crimped aluminum pan used as reference. Tg was considered at the mid-point temperature of the endothermic drift in the heating curve. All DSC tests were carried out under a $2 \mathrm{ml} / \mathrm{min}$ flow of nitrogen to prevent oxidation.

\subsubsection{Determine of Average Molecular Weight and Polydispersity Index}

The molecular weight and molecular weight distribution (polydispersity index, Mw/Mn) of copolymers were determined by gel permeation chromatography (GPC, waters 515 HPLC pump, USA), that is equipped with a refractive index detector, using a series of high-resolution columns (waters, styragel HR4E $7.8 \mathrm{~mm} \times 300 \mathrm{~mm}$ and styragel HR3E $7.8 \times 300 \mathrm{~mm}$ ) and tetrahydrofuran (THF) as a mobile phase. Tetrahydrofuran was used as eluent at $45^{\circ} \mathrm{C}$ and polystyrene standards (polymer laboratories, Inc. USA). Total time for analyzing of samples which were injected after dissolving in THF solvent was 10 - 15 minutes.

\subsubsection{Determination of Particle Size and Morphology of the Drug-Loaded Nanoparticle}

The morphology of the polymeric nanoparticles was observed using a scanning electron microscopy (SEM). For the scanning electron microscopy (SEM), the lyophilized nanoparticles were placed on a double stick tape over aluminum stubs to get a uniform layer of particles. Sam- ples were then gold-coated using a sputter gold coater. Gold coated particle samples were cooled over liquid nitrogen prior to SEM observations to avoid their melting under high magnification due to the electron beam exposure (Leo Electron Microscopy Ltd., Cambridge, UK). Prior to examination, samples were prepared on aluminum stubs and coated with gold under argon atmosphere by means of a sputter coater.

\subsubsection{Determination of the Albumin Entrapment Efficiency}

Loaded drug quantity was determined according to the following method after nanoparticles were formed, unbound albumin was separated by centrifugation for 10 min, and the precipitate nanoparticles were separated. The separated nanoparticles was then lyophilized and resulting powder containing the albumin -loaded nanoparticles was dissolved in DMC to obtain a clear solution and analyzed UV spectrophotometrically (Shimadzu UV160). Loading capacity was expressed in terms of entrapped drug content, and entrapment efficiency (EE \%) as follows:

$$
\begin{aligned}
E E \% & =(\text { entrapped drug content/initial drug content }) \\
& \times 100
\end{aligned}
$$

\section{Result and Discussion}

\subsection{Synthesis and Characterization of Star-Shaped PLGA- $\beta$-CD Copolymer}

Star-shaped polymers because of only one branched center are the simplest branched polymers. These polymers can be produced by chemically linking preformed polymers (polymer first method) or by growing polymer chains from a multifunctional initiator (core first method). Coupling agents with a compressed dendritic construction have been used to enhance the functionality of the star polymers. Branched polyesters consisting of PVA grafted with chains of PLGA is typical polyester used for pharmaceutical use. In the present study, $\beta$-CD was proffered to previously use multifunctional initiators as the potential of CDs and their derivatives as new biodegradable carrier for peptides, proteins, and oligonucleotides with emphasize on the interaction between CDs, these drug candidates, and various endogenous molecules. Chemical structure of star shaped PLGA- $\beta$-CD copo- 
lymer is shown in Figure 1. The copolymer was synthesized by bulk polymerization of the lactones (LA and GA) in the presence of the $\beta$-CD using sn-octoate as catalyst. The primary hydroxyl groups of $\beta$-CD are expected to begin the polymerization of LA and GA, while it is rather debatable whether the secondary $\mathrm{OH}$ will act alike in view of its stereochemical inhibition. The yield of polymer synthesis after precipitation with cold ethers given in Table 1. Per mole of $\beta$-CD and sn-octoate in all polymerization reactions was 0.1 and 0.05 mole and the variable molar ratios of LA and GA were used. Relatively low amount of $\beta$-CD and catalyst was used in order to obtain high molecular weight polymers. Table 1 and GPC choromarograms in Figure 2 shows that increasing the molar ratio of LA to GA, yield of polymerization and the molecular weight of the final polymer increase and the best results in molar ratio of 3 to 1 (I) is obtained. This shows the higher activity of LA in copolymerization. Another reactions with variable molar of cyclodextrin were prepared and observed that increasing molar ratio of cyclodextrin growing polymers very minor and the molecular weight of the polymers were low, it related to complexation of monomers in the internal cavity of the cyclodextrin and prevents the initiation of the polymerization reaction. Also, decreasing of cyclodextrin molar ratio from 0.1 mole lead to the formation of linear chains of PLGA. Therefore, the appropriate concentration of cyclodextrin was considered 0.1 moles.

\subsection{DSC Measurements}

DSC is usually used for study of physical state of nanoparticles. DSC was used to determine the thermal properties of star-shaped copolymers. The expected decrease in the glass transition temperatures $\mathrm{Tg}$ and melting points Tm could be observed (Table 1). The reduction of interactions between the star-shaped polyester molecules due to their branched structure lowered Tg and Tm compared to linear PLGA copolymers. As shown in Table 1 increasing lactide in a certain concentration melting point of copolymer were increased becouse lactide increasing number of methyl groups and the amorphous nature of the polymer is more.

\subsection{NMR and FT-IR Spectra of Copolymer}

The chemical composition of the copolymers was determined with H-NMR and C-NMR by integrating the signals pertaining to each monomer. The freeze dried particles dissolved in DMSO showed the same spectra as that of the original copolymer. This indicated that the composition for the particles was exactly the same as that of the original matrix. Although the ${ }^{1} \mathrm{H}$ NMR spectra (Figure 3) of star-branched polyesters show the resonance signals for typical linear PLGA protons (the mul-

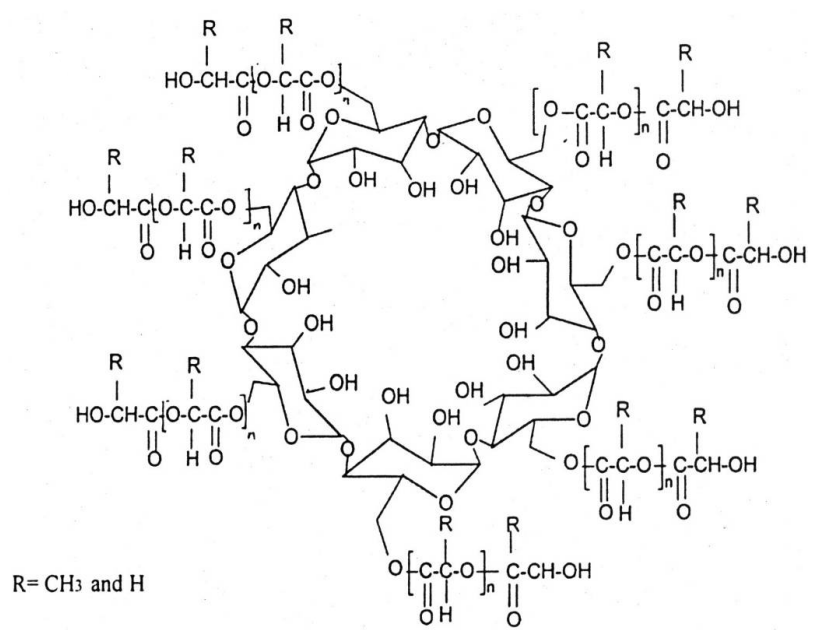

Figure 1. Chemical structure of PLGA- $\beta$-CD star-shaped copolymer.

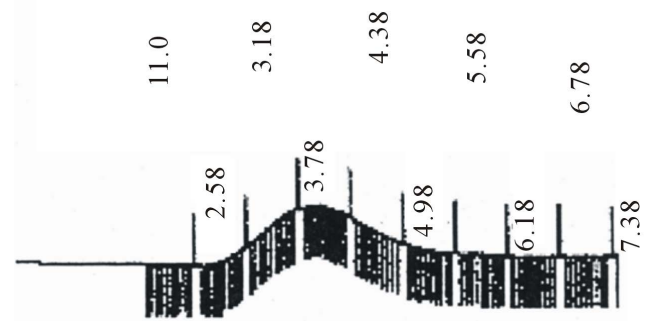

(a)

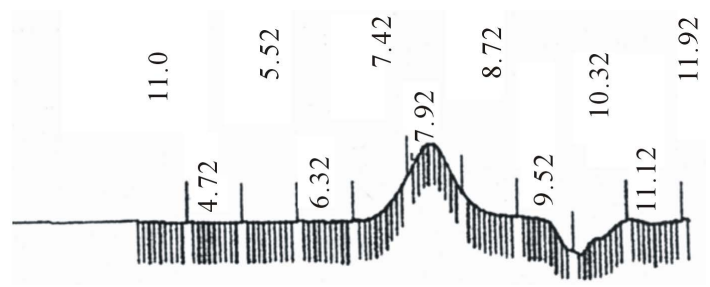

(b)

Figure 2. GPC choromarograms of PLGA- $\beta$-CD copolymer, a(I) and $b$ (IV).

tiplets at 5.2 and $4.7 \mathrm{ppm}$ related to the $\mathrm{LA} \mathrm{CH}$ and the GA CH2 respectively, and the singlet at 2.2 ppm correspond to $\mathrm{CH} 3$ of $\mathrm{LA}$ ), there are some other peaks, due to the incorporation of $\beta$-CD. The $\mathrm{C}^{2}-\mathrm{C}^{6}$ methine and methylene protons of $\beta$-CD appeared at $4-4.5 \mathrm{ppm}$ the assignment of the peak at $4 \mathrm{ppm}$ to the methylene groups of $\beta$-CD was supported by its increase in resonance intensity with an increase in the $\beta$-CD molar ratio. The presence of secondary -OH groups at the chain end and/or unreacted -OH groups of polyol could be appear at 4 and 4.3 ppm which may overlap with the peak of methane protons. LA terminal $-\mathrm{OH}$ appears at $2 \mathrm{ppm}$. The signals of the PLGA- $\beta$-CD in the ${ }^{13} \mathrm{C}$ NMR spectra (Figure 4) were 21.07 ppm LA CH3, 61 ppm LA CH, 173 ppm esteric CO (polylactide-GA ester) 170.07 ppm methylene $\mathrm{CH}$ and 17.03 ppm (CH3). The connecting 
2

s

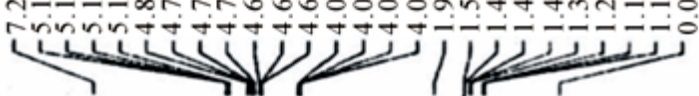

Current Data Parameters

NAME another

ExPNO

PROCNO 1

F2-Acquisition Parameters

Data_ 20040711

$\begin{array}{ll}\text { Time } & 10.52 \\ \text { INSTRUH } & \end{array}$

PROBHO $5 \mathrm{~mm}$ QNP1H

TO $\quad 32760$

SOLVENT COC13

NS $\quad 10$

SXH $\quad 8278.146 \mathrm{~Hz}$

FIDAES $\quad 0.252629 \mathrm{~Hz}$

$\begin{array}{lr}0.252629 \mathrm{HZ} \\ \text { AQ } & 1.9792372 \mathrm{sec}\end{array}$

$\begin{array}{lr}\text { AQ } & 1.9792372 \\ \text { RG } & 22.5\end{array}$

DW $\quad 50.400$ usec

DE $\quad 5.00 \mathrm{uscc}$

$300.0 \mathrm{~K}$

$01 \quad 1.00000000 \mathrm{sec}$

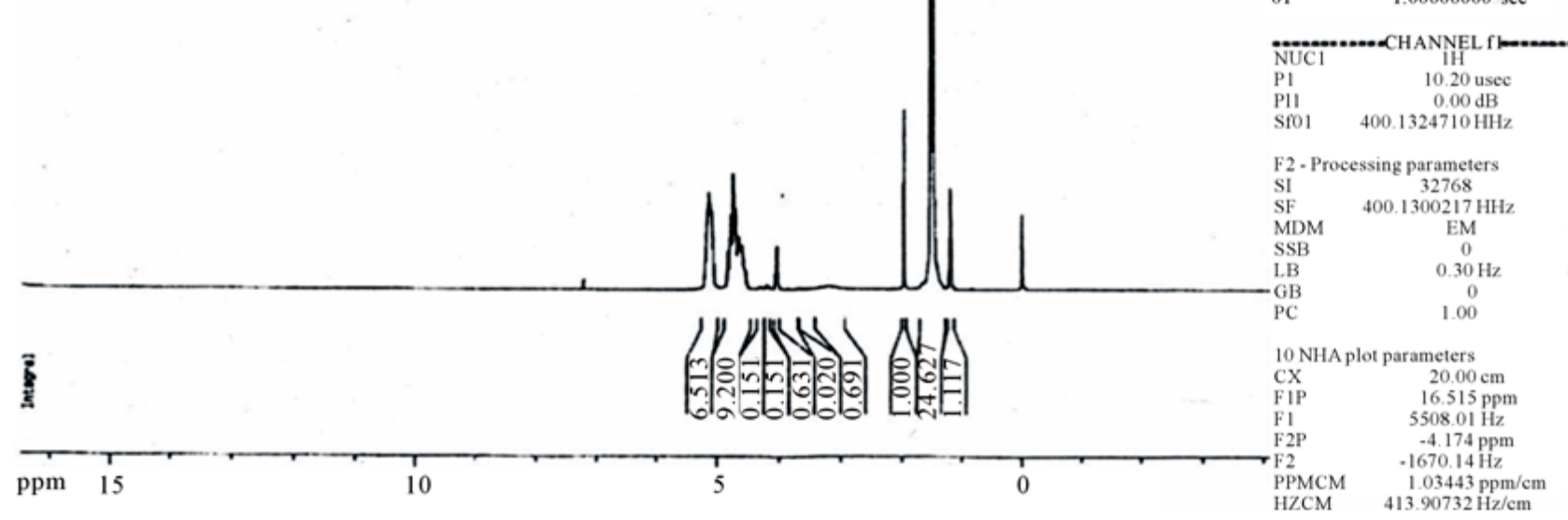

Figure 3. ${ }^{1} \mathrm{H}$ NMR spectrum of PLGA- $\beta$-CD copolymer.

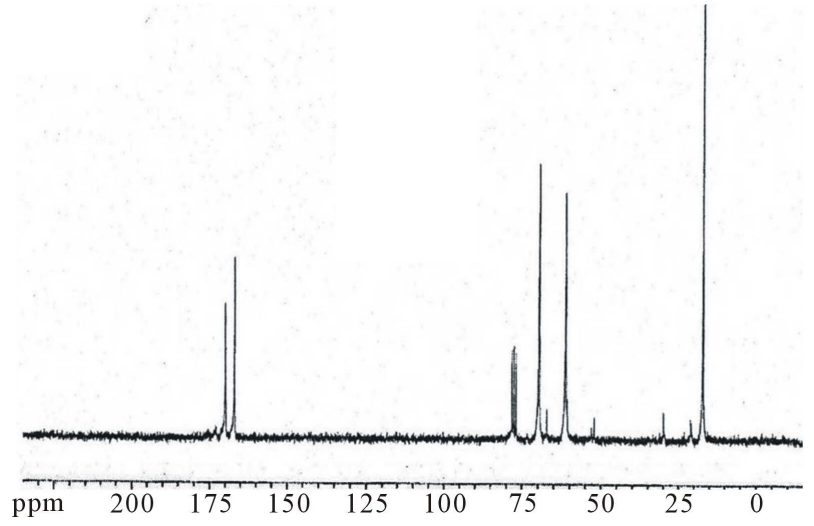

Figure $4 .{ }^{13} \mathrm{C}$ NMR spectrum of PLGA- $\beta$-CD copolymer.

ester bond appeared at about 169 ppm CD-LA ester, and $\beta$-CD-CH2-OCO at about 61.2. The FT-IR spectra of these copolymers showed a broad absorption at 2990 $\mathrm{cm}^{-1}$ indicating the presence of -OH groups. In addition, an absorption band at $1760 \mathrm{~cm}^{-1}$ confirms the formation of $-\mathrm{O}-\mathrm{C}-\mathrm{O}$ ester bonds (Figure 5). The GPC traces of the star-shaped PLGA- $\beta$-CD copolymers give monodisperse curves. In fact, this is in agreement with previous publications where sn-octoate was used for LA-glycerol or LA pentaerythrol. Therefore, it could be suggested that nitiation of polymerization occurs via the polyol

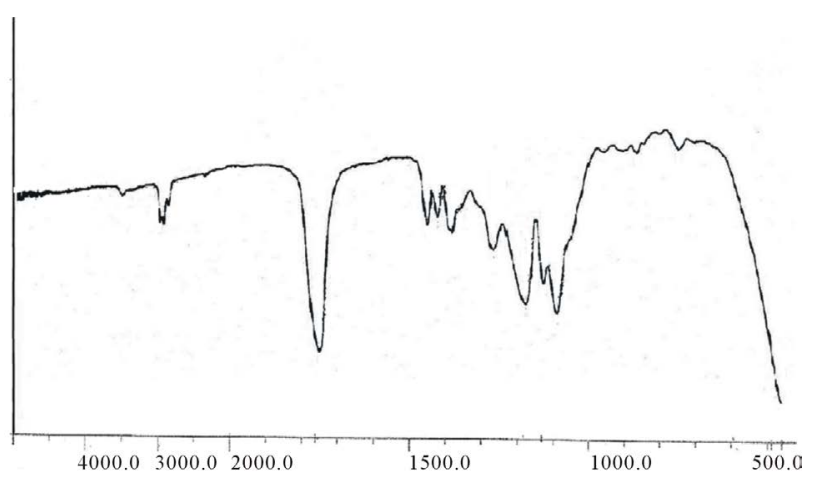

Figure 5. FT-IR spectrum of PLGA- $\boldsymbol{\beta}$-CD copolymer.

$(\beta-\mathrm{CD})$.

\subsection{Characterization of Made of PLGA- $\beta$-CD Copolymer Nanoparticles}

Star-shaped PLGA- $\beta$-CD(I) copolymer nanoparticles were prepared by a double emulsion-solvent evaporation method in the presence PVA. Figures 6 and 7 shows the SEM and TEM micrographs of the star-shaped PLGA- $\beta$ CD nanoparticles. SEM and TEM micrographs of all nanoparticles revealed relatively spherical morphology. The average particle size of samples was $80-210 \mathrm{~nm}$. 


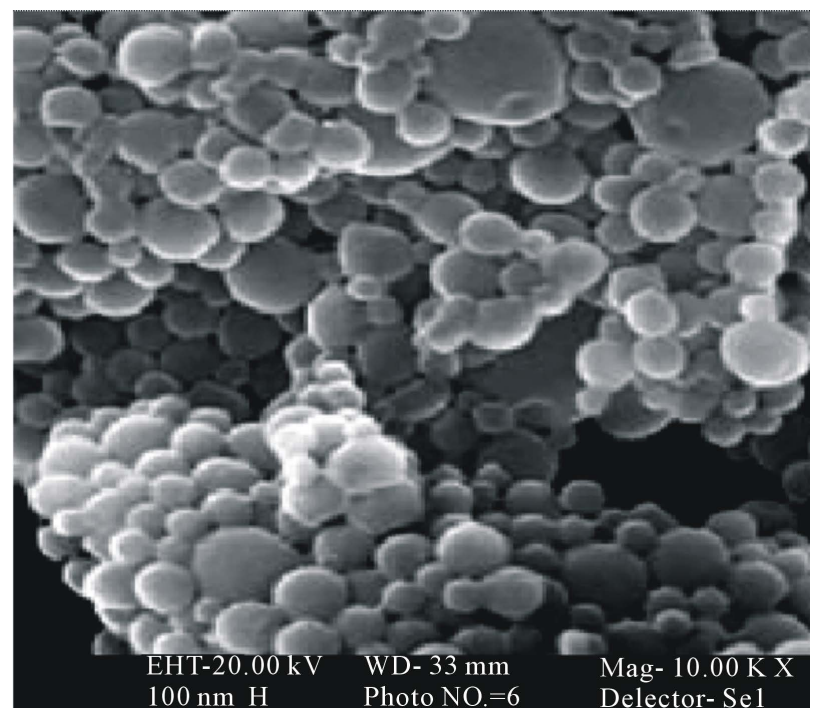

(a)

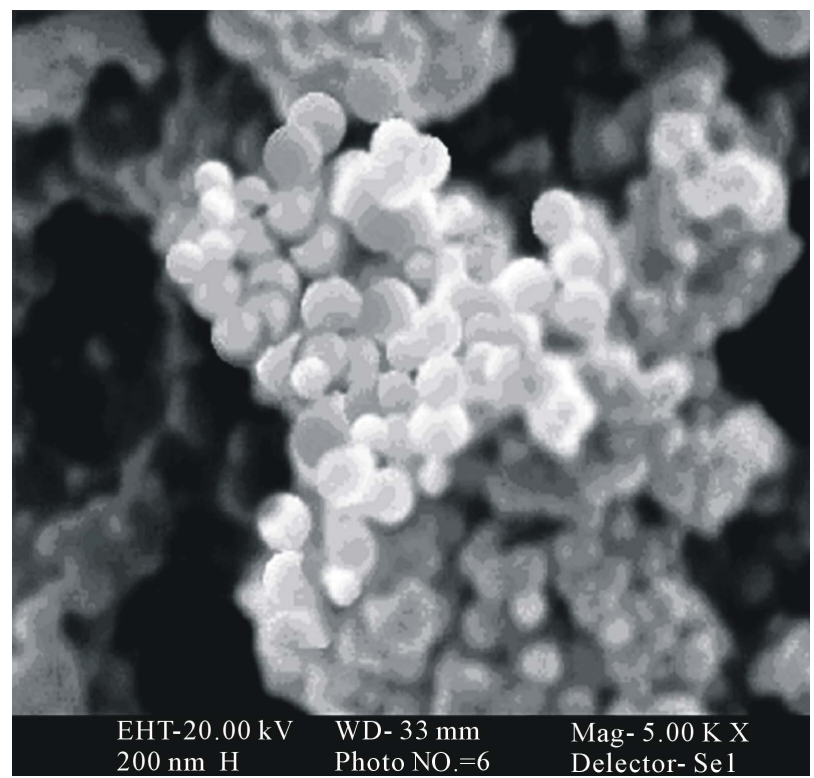

(b)

Figure 6. Scanning electron microscopy (SEM) of nanooparticles surface fabricated by PLGA- $\beta$-CD(I) without albumin (a), and PLGA- $\beta$-CD(I) with albumin (b).

\subsection{Effect of Temperature on Yield of Polymerization and Molecular Weight}

Polymerizations were conducted in solvent-free and melt conditions. Polymerization performed in $130^{\circ} \mathrm{C}$ and $150^{\circ} \mathrm{C}$ and $180^{\circ} \mathrm{C}$. Polymerization yield and the molecular weight of the polymers for sample (I) is summarized in Table 2. As Table 2 increasing the temperature of the polymerization reaction from $130^{\circ} \mathrm{C}$ to $180^{\circ} \mathrm{C}$ the yield of polymerization increased and concentration of unreacted monomers reduced. Also increase in the reaction temperature leads to a decrease in the molecular weight of the polymers. As shown in Table 2, between the different

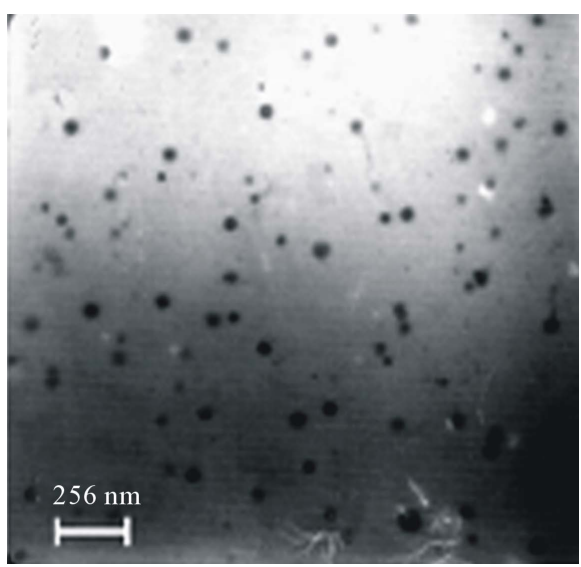

(a)

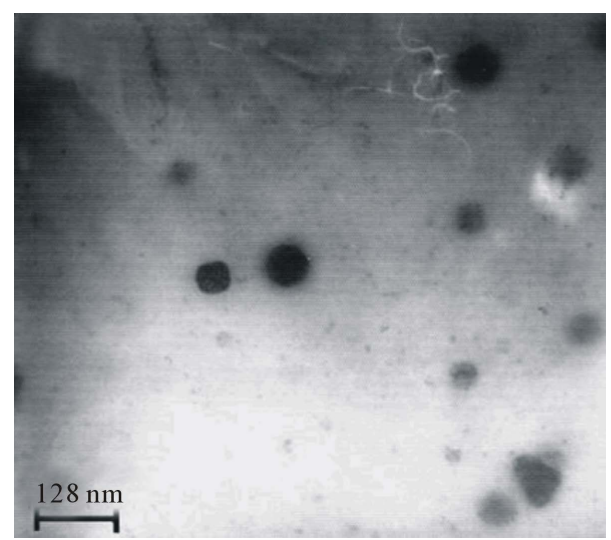

(b)

Figure 7. Transmission electron microscopy (TEM) nanoparticles surface fabricated by in $50 \mathrm{mg} / \mathrm{ml}$ of PLGA- $\beta$-CD copolymer (a), and in $35 \mathrm{mg} / \mathrm{ml}$ of PLGA- $\beta$-CD copolymer (b).

Table 2. The effect of temperature on the reaction yield and the molecular weight of the final polymer.

\begin{tabular}{cccc}
\hline polymer & temperature $\left({ }^{\circ} \mathrm{C}\right)$ & Yield $(\%)$ & $\begin{array}{c}\text { molecular } \\
\text { weight }\end{array}$ \\
\hline (PLGA- $\beta$-CD)I & 130 & 60 & 11,000 \\
$($ PLGA- $\beta$-CD)I & 150 & 65 & 12,770 \\
$($ PLGA- $\beta$-CD)I & 180 & 68 & 9850 \\
\hline
\end{tabular}

temperatures, $150^{\circ} \mathrm{C}$ is the best temperature for polymerization reaction.

\subsection{Effect of Copolymer Concentration on the Nanoparticles Properties}

Concentration of the polymer in the emulsion is an important factor on nanoparticles properties. As shown in Tables 3 and 4 polymer molecular weight oil/water ratio and temperature plays an important role in particle size.

As shown in Table 3 increase concentration of polymer microparticle size and efficiency is Mykrvankpsvlasyvn. The reason for this is explained so thick and viscous po- 
Table 3. The effect of polymer concentration on the nanoparticles properties.

\begin{tabular}{ccccc}
\hline polymer (mg/ml) & $\begin{array}{c}\text { PVA } \\
(\mathrm{mg} / \mathrm{ml})\end{array}$ & $\begin{array}{c}\text { Albumin } \\
(\%)\end{array}$ & $\begin{array}{c}\text { encapsulation } \\
\text { efficiency } \\
(\text { EE \%) }\end{array}$ & $\begin{array}{c}\text { Particle } \\
\text { Size(nm) }\end{array}$ \\
\hline 35 & 0.1 & 10 & 45 & $85 \pm 10$ \\
50 & 0.1 & 10 & 57.9 & $100 \pm 10$ \\
80 & 0.1 & 10 & 65 & $170 \pm 10$ \\
\hline
\end{tabular}

Table 4. Effect of aqueous phase volume on particle size and EE.

\begin{tabular}{cccc}
\hline $\begin{array}{c}\text { volume ratio } \\
\begin{array}{c}\text { Aqueous: } \\
\text { organic }\end{array}\end{array}$ & Albumin (\%) & $\begin{array}{c}\text { encapsulation } \\
\text { efficiency } \\
\text { (EE \%) }\end{array}$ & $\begin{array}{c}\text { Particle } \\
\text { Size(nm) }\end{array}$ \\
\hline $1: 15$ & 10 & 55 & $150 \pm 10$ \\
$1: 25$ & 10 & 61 & $95 \pm 10$ \\
$1: 45$ & 10 & 70 & $80 \pm 10$ \\
\hline
\end{tabular}

lymer solution cannot be easily broken into smaller droplets. On the other hand, the formation of a solid shell around Mykrvzrat high concentration of polymer in the polymer layer creates a viscous drop Mykrvzrat faster done. External aqueous phase of the emulsion layer to prevent diffusion of albumin. The high concentration of polymer increases efficiency and reduces nanoparticles initial burst release is albumin.

\subsection{Effect of Aqueous Phase Volume on Particle Size and EE}

According to Table 4 increasing in the aqueous phase volume led to a decrease of nanoparticles average size. Coalescence of droplets could be prevented by a large quantity of internal phase. An increase in the internal aqueous could lead to an increase in EE. The Precipitation of the polymer solution phase was accelerated and the hardening time was shortened with the increase of inner phase.

\subsection{Effect of Temperature on the Albumin Loaded PLGA- $\beta$-CD Copolymers Properties with}

Temperemper of preparing nanoparticles known to be a key factor to influence the size and encapsulation efficiency of nanoparticles. As shown in Table 5 increasing the temperature from $10^{\circ} \mathrm{C}$ to $28^{\circ} \mathrm{C}$ reduce thenanoparticle size becouse the emulsion $\mathrm{W} / \mathrm{O} / \mathrm{W}$ have lower viscosity in high temperatures, so it is easier to break it into smaller droplets.

When the temperature of encapsulation raised to $38^{\circ} \mathrm{C}$ particles size increased due to the high evaporation rate of the solvent. In addition Table 5 shows that in $10^{\circ} \mathrm{C}$ to $38^{\circ} \mathrm{C}$ encapsulation efficiency is higher than other temperatures. Differences in encapsulation efficiency depend
Table 5. Effect of temperature on the albumin loaded PLGA- $\boldsymbol{\beta}$-CD copolymers properties.

\begin{tabular}{cccc}
\hline $\begin{array}{c}\text { Temperature } \\
\left({ }^{\circ} \mathrm{C}\right)\end{array}$ & Albumin (\%) & $\begin{array}{c}\text { encapsulation } \\
\text { efficiency } \\
\text { (EE \%) }\end{array}$ & Particle Size(nm) \\
\hline 10 & 10 & 69 & 170 \\
22 & 10 & 52 & 100 \\
28 & 10 & 58 & 85 \\
33 & 10 & 63 & 125 \\
38 & 10 & 67 & 150 \\
\hline
\end{tabular}

on various parameters such as condition of reaction, nanoparticle size, initial loading, polymer concentration, polymer molecular weight, polymer composition, and special techniques are particle. Formation of a solid layer of polymer around nanoparticle increase efficiency). Nanoparticles which prepared at $38^{\circ} \mathrm{C}$ quickly become solid and this increased efficiency of encapsulation. The efficiency of prepared nanoparticles in temperatures below and above will be the same $[27,28]$.

\section{Conclusion}

Biodegradable nanoparticles, as drug delivery paradigms, have been extensively used for delivery of wide ranges of small molecules as well as macromolecules such as peptides, proteins and genes [29]. The morphological modification may improve the physicochemical characteristics of the biodegradable polymers. Star-shaped PLGA- $\beta$ CD copolymers with different molar ratios of monomers were synthesized and used for the preparation of albumin nanoparticles [30]. In conclusion, the results obtained in the present study showed that star-shaped PLGA- $\beta$-CD could be synthesized by ring-opening polymerization of the LA and GA in the presence of $\beta$-CD. The albumin loaded nanoparticles could be prepared by double emulsion technique. It was found that the copolymers' composition influences the mean geometric diameter of the albumin loaded nanoparticles, as well as their loading efficiency. These results showed that PLGA- $\beta$-CD nanoparticles could be an effective carrier for anticancer drug delivery. An increase in the internal aqueous phase volume led to a decrease in particles' average size. The high entrapment efficiency (EE) (about 70\%) was obtained for $80 \mathrm{~nm}$ particles [31,32].

\section{Competing Interests}

The authors declare that they have no competing interests.

\section{Authors' Contributions}

$\mathrm{KN}$ conceived of the study and participated in its design and coordination. AA and SD participated in the se- 
quence alignment and drafted the manuscript. All authors read and approved the final manuscript.

\section{Acknowledgements}

The authors thank Department of Medical Nanotechnology, Faculty of Advanced Medical Science of Tabriz University, and Department of Science, Ahar Branch, Islamic Azad University, Ahar, Iran for all supports provided.

\section{REFERENCES}

[1] S. P. Schwederman, M. Cardamone, M. R. Brandon, A. Klibanov and R. Langer, "Stability of Proteins and Their Delivery from Biodegradable Microspheres,” In: S. Cohen and H. Bernstein, Eds., Microparticulate Systems for the Delivery of Proteins and Vaccines, Marcel Dekker, New York, 1996, pp. 1-50.

[2] D. Blanco and M. J. Alonso, "Protein Encapsulation and Release from Poly(lactide-co-glycolide) Microspheres: Effect of the Protein and Polymer Properties and of the Co-Encapsulation of Surfactants," European Journal of Pharmaceutics and Biopharmaceutics, Vol. 45, 1998, pp. 285-294.

[3] S. Alimohammadi, R. Salehi, N. Amini and S. Davaran, "Synthesis and Physicochemical Characterization of Biodegradable PLGA-Based Magnetic Nanoparticles Containing Amoxicilin,” Bulletin of the Korean Chemical Society, Vol. 33, No. 10, 2012, pp. 3225-3232.

http://dx.doi.org/10.5012/bkcs.2012.33.10.3225

[4] C.-H. Zheng, J.-Q. Gao, Y.-P. Zhang and W.-Q. Liang, "A Protein Delivery System: Biodegradable AlginateChitosan-Poly(lactic-co-glycolic acid) Composite Microspheres," Biochemical and Biophysical Research Communications, Vol. 323, No. 4, 2004, pp. 1321-1327. http://dx.doi.org/10.1016/j.bbrc.2004.09.007

[5] H. B. Ravivarapu, K. Burton and P. K. Deluca, "Polymer and Microsphere Blending to alter the Release of a Peptide from PLGA Microspheres," European Journal of Pharmaceutics and Biopharmaceutics, Vol. 50, No. 2, 2000, pp. 263-270. http://dx.doi.org/10.1016/S0939-6411(00)00099-0

[6] J. K. Li, N. Wang and X. S. Wu, “A Novel Biodegradable System Based on Gelatin Nanoparticles and Poly(lacticco-glycolic Acid) Microspheres for Protein and Peptide Drug Delivery,” Pharmacological Research, Vol. 86, 1997, pp. 891-895.

[7] M. Diwan and T. G. Park, "Pegylation Enhances Protein Stability Stability during Encapsulation in PLGA Microspheres,” Journal of Controlled Release, Vol. 73, No. 2-3, 2001, pp. 233-244.

http://dx.doi.org/10.1016/S0168-3659(01)00292-9

[8] F. Karen, K. Griebenow, L. Hsieh, A. M. Klibanov and R. Langer, "FTIR Characterization of the Secondary Structure of Proteins Encapsulated with PLGA Microspheres," Journal of Controlled Release, Vol. 58, No. 3, 1999, pp. 357-366.

[9] J. Kang and S. P. Schwendeman, "Comparison of the
Effects of $\mathrm{Mg}(\mathrm{OH})_{2}$ and Sucrose on the Stability of Bovine Serum Albumin Encapsulated in Injectable Poly(d,llactide-co-glycolide) Implants,” Biomaterials, Vol. 23, No. 1, 2002, pp. 239-245.

http://dx.doi.org/10.1016/S0142-9612(01)00101-6

[10] M. L. Gonzalez-Rodrıguez, M. A. Holgado, C. SanchezLafuente, A. M. Rabasco and A. Fini, "Alginate/Chitosan Particulate Systems for Sodium Diclofenac Release,” International Journal of Pharmaceutics, Vol. 232, No. 1-2, 2002, pp. 225-234. http://dx.doi.org/10.1016/S0378-5173(01)00915-2

[11] X. Z. Shu and K. J. Zhu, “The Release Behavior of Brilliant Blue from Calcium-Alginate Gel Beads Coated by Chitosan: The Preparation Method Effect," European Journal of Pharmaceutics and Biopharmaceutics, Vol. 53, No. 2, 2002, pp. 193-201.

http://dx.doi.org/10.1016/S0939-6411(01)00247-8

[12] D. W. Lee, S. J. Hwang, J. B. Park and H. J. Park, "Preparation and Release Characteristics of Polymer-Coated and Blended Alginate Microspheres,” Journal of Microencapsulation, Vol. 20, 2003, pp. 179-192.

[13] M. Diwan and T. G. Park, "Stabilization of Recombinant Interferon-A by Pegylation for Encapsulation in PLGA Microspheres,” International Journal of Pharmaceutics, Vol. 252, No. 1-2, 2003, pp. 111-122. http://dx.doi.org/10.1016/S0378-5173(02)00636-1

[14] M. D. Blanco and M. J. Alonso, “Development and Characterization of Protein-Loaded Poly(lactide-co-glycolide) Nanospheres,” European Journal of Pharmaceutics and Biopharmaceutics, Vol. 43, No. 3, 1997, pp. 287-294. http://dx.doi.org/10.1016/S0939-6411(97)00056-8

[15] F. Lallemand, O. Felt-Baeyens, K. Besseghir, F. BeharCohen and R. Gurny, "Cyclosporine Adelivery to the Eye: A Pharmaceutical Challenge,” European Journal of Pharmaceutics and Biopharmaceutics, Vol. 56, No. 3, 2003, pp. 307-318.

http://dx.doi.org/10.1016/S0939-6411(03)00138-3

[16] T. Loftsson, A. Magnudottir, M. Masson and J. F. Sigurjonsdottir, "Self-Association and Cyclodextrin Solubilization of Drugs," Journal of Pharmaceutical Sciences, Vol. 91, No. 11, 2002, pp. 2307-2316.

http://dx.doi.org/10.1002/jps.10226

[17] T. Loftsson, K. Matthiasson and M. Masson, "The Effect of Organic Salts on Cyclodextrin Solubilization of Drugs,” International Journal of Pharmaceutics, Vol. 262, No. 1-2, 2003, pp. 101-107. http://dx.doi.org/10.1016/S0378-5173(03)00334-X

[18] G. Orive, R. M. Hernandez, A. R. Gascon and J. L. Pedraz, "Micro and Nano Drug Delivery Systems in Cancer Therapy,” Cancer Therapy, Vol. 3, 2005, pp. 131-138.

[19] Y. P. Li, Y. Pei, X. Zhang, Z. Gu, Z. Zhou, W. Yuan, J. Zhou, J. Zhu and X. Gao, "PEGylated PLGA Nanoparticles as Protein Carriers, Synthesis, Preparation and Biodistribution in Rats," Journal of Controlled Release, Vol. 71, No. 2, 2001, pp. 203-211. http://dx.doi.org/10.1016/S0168-3659(01)00218-8

[20] A. Ahmadi, H. Shirazi, N. Pourbagher, A. Akbarzadeh and K. Omidfar, "An Electrochemical Immunosensor for Digoxin Using Core-Shell Gold Coated Magnetic Nano- 
particles as Labels,” Molecular Biology Reports, 2014, Epub Ahead of Print.

[21] K. Nejati-Koshki, A. Akbarzadeh, M. Pourhasan-Moghadam, A. Abhari and H. Dariushnejad, "Inhibition of Leptin and Leptin Receptor Gene Expression by Silibinin-Curcumin Combination," Asian Pacific Journal of Cancer Prevention, Vol. 14, No. 11, 2013, pp. 6595-6599.

[22] M. Pourhassan-Moghaddam, M. Rahmati-Yamchi, A. Akbarzadeh, H. Daraee, K. Nejati-Koshki, Y. Hanifehpour and S. W. Joo, "Protein Detection through Different Platforms of Immuno-Loop-Mediated Isothermal Amplification," Nanoscale Research Letters, Vol. 8, No. 8, 2013, p. 485.

[23] M. Mollazade, K. Nejati-Koshki, A. Akbarzadeh, Y. Hanifehpour, N. Zarghami and S. W. Joo, "PAMAM Dendrimers Arugment Inhibitory Effect of Curcumin on Cancer Cell Proliferation: Possible Inhibition of Telomerase," Asian Pacific Journal of Cancer Prevention, Vol. 14, No. 11, 2013, pp. 6925-6928. http://dx.doi.org/10.7314/APJCP.2013.14.11.6925

[24] R. Rezaei-Sadabady, N. Zarghami, A. Barzegar, A. Eidi, A. Akbarzadeh and M. Rezaei-Tavirani, "Studies of the Relationship between Structure and Antioxidant Activity in Interesting Systems, Including Tyrosol, Hydroxytyrosol Derivatives Indicated by Quantum Chemical Calculations," Soft, Vol. 2, No. 2, 2013, pp. 13-18.

[25] Y. J. Hu, Y. Liu, Z. B. Pi and S. S. Qu, "Interaction of Cromolyn Sodium with Human Serum Albumin: A Fluorescence Quenching Study,” Bioorganic \& Medicinal Chemistry, Vol. 13, No. 24, 2005, pp. 6609-6614. http://dx.doi.org/10.1016/j.bmc.2005.07.039

[26] E. Alarcon, A. M. Edwards, A. Aspee, F. E. Moran, C. D. Borsarelli, E. A. Lissi, D. Gonzalez-Nilo, H. Poblete and J. C. Scaiano, "Photophysics and Photochemistry of Dyes Bound to Human Serum Albumin Are Determined by the Dye Localization," Photochemical \& Photobiological
Sciences, Vol. 9, No. 1, 2010, pp. 93-102. http://dx.doi.org/10.1039/b9pp00091g

[27] A. Valizadeh, H. Mikaeili, M. Samiei, S. M. Farkhani, N. Zarghami, M. Kouhi, A. Akbarzadeh and S. Davaran, "Quantum Dots: Synthesis, Bioapplications, and Toxicitynanoscale,” Research Letters, Vol. 7, 2012, p. 480.

[28] A. Akbarzadeh, M. Samiei, S. W. Joo, M. Anzaby, Y. Hanifehpour, H. T. Nasrabadi and S. Davaran, "Synthesis, Characterization and in Vitro Studies of AdriamaycinEncapsulated Magnetic Nanoparticles Grafted to Smart Copolymers on A549 Lung Cancer Cell Line,” Journal of Nanobiotechnology, Vol. 10, No. 1, 2012, p. 46. http://dx.doi.org/10.1186/1477-3155-10-46

[29] A. Akbarzadeh, R. Rezaei-Sadabady, S. Davaran, S. W. Joo, N. Zarghami, Y. Hanifehpour, M. Samiei, M. Kouhi and K. Nejati-Koshki, "Liposome: Classification, Preparation, and Applications,” Nanoscale Research Letters, Vol. 8, No. 1, 2013, p. 102. http://dx.doi.org/10.1186/1556-276X-8-102

[30] A. Akbarzadeh, N. Zarghami, H. Mikaeili, D. Asgari, A. M. Goganian, K. Khaksar, S. Mohammad and D. Soodabeh, "Synthesis, Characterization and in Vitro Evaluation of Novel Polymer-Coated Magnetic Nanoparticles for Controlled Delivery of Adriamaycin,” Nanotechnology, Science and Applications, Vol. 5, 2012, pp. 1-13.

[31] A. Akbarzadeh, H. Mikaeili, N. Zarghami, R. Mohammad, A. Bsrkhordari abd S. Davaran, "Preparation and In-Vitro Evaluation of Adriamaycin-Encapsulated $\mathrm{Fe}_{3} \mathrm{O}_{4}$ Magnetic Nanoparticles Modified with Biocompatible Copolymer," International Journal of Nanomedicine, Vol. 7, 2012, pp. $1-16$.

[32] A. Akbarzadeh, M. Samiei and S. Davaran, "Magnetic Nanoparticles: Preparation, Physical Properties, and Applications in Biomedicine,” Nanoscale Research Letters, Vol. 7, No. 1, 2012, p. 144. http://dx.doi.org/10.1186/1556-276X-7-144 